\title{
TIERNO MONÉNEMBO, Bled
}

\section{Emanuela Cacchioli}

\section{(C) OpenEdition}

Journals

\section{Edizione digitale}

URL: https://journals.openedition.org/studifrancesi/14207

DOI: 10.4000/studifrancesi. 14207

ISSN: 2421-5856

\section{Editore}

Rosenberg \& Sellier

\section{Edizione cartacea}

Data di pubblicazione: 1 août 2018

Paginazione: 373-374

ISSN: 0039-2944

\section{Notizia bibliografica digitale}

Emanuela Cacchioli, «TIERno monénembo, Bled», Studi Francesi [Online], 185 (LXII | II) | 2018, online dal 01 août 2018, consultato il 16 novembre 2021. URL: http://journals.openedition.org/studifrancesi/14207 ; DOI: https://doi.org/10.4000/studifrancesi.14207

Questo documento è stato generato automaticamente il 16 novembre 2021.

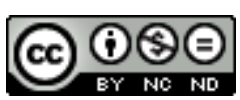

Studi Francesi è distribuita con Licenza Creative Commons Attribuzione - Non commerciale - Non opere derivate 4.0 Internazionale. 


\title{
TIERNO MONÉNEMBO, Bled
}

\author{
Emanuela Cacchioli
}

\section{NOTIZIA}

TIERNO MONÉNEMBO, Bled, Paris, Seuil, 2016, 204 pp.

1 Una lunga fuga nell'Algeria rurale degli anni Ottanta, intervallata da momenti di reclusione forzata, da situazioni drammatiche in cui la violenza sembra prevalere sulla giustizia. Potrebbe essere questo il riassunto, ridotto all'osso, dell'ultimo romanzo di Tierno Monénembo. L'autore, originario della Guinea, insignito del Grand Prix de la Francophonie nel 2017, ci regala una scrittura coinvolgente in cui la protagonista, Zoubida, si rivolge a un uomo, Alfred, al quale racconta, in una sorta di letteraconfessione, tutto ciò che le è accaduto negli ultimi tempi. La vicenda inizia in medias res, in un «bled», uno dei tanti villaggi in cui la giovane donna trova rifugio, dopo la fuga dal suo paese natale: Aïn Guesma. Zoubida è ricercata dalla polizia. Scopriremo solo in seguito, attraverso il suo racconto, che è fuggita perché ha avuto un figlio da un docente (algerino di nascita e francese d'adozione) che non ha voluto riconoscerlo. Da quel momento hanno inizio le sue vicissitudini. Zoubida, che sembra segnata dal destino alla nascita a causa di «une stigmate au front, une stigmate en forme d'étoile» (p. 14), fugge di notte. Attraversa boschi e fiumi, ricorre a autobus, autostop, asini, auto che guida lei stessa. La piccola creatura che l'accompagna le dà una forza immensa per sopportare soprusi e ingiustizie. Nonostante questo, il suo destino sembra segnato: passa da un aguzzino a un altro e la sua fuga trova un primo momento di reclusione in una sorta di harem-bordello, in cui Mounir la tiene prigioniera. Dopo aver sopportato per qualche tempo violenze fisiche e psicologiche, uccide l'uomo e fugge da quel luogo di costrizione. La corsa sarà breve. Ricercata dalla polizia per omicidio, sarà incarcerata e processata. La condanna non può che essere l'ergastolo. Tutto sembra perduto: viene separata dal figlio e rinchiusa in una cella angusta da condividere con altre detenute. Zoubida ci appare come una folle disperata, vittima di un destino crudele. La forza che l'ha condotta alla fuga è svanita. La giovane donna è in preda a un torpore che la rende apatica, quasi incosciente di ciò che le sta accadendo. Eppure, quando tutto sembra 
perduto, un incontro alquanto paradossale tra le mura del carcere le offre quella via d'uscita che era diventata ormai impossibile. In un primo momento è la letteratura che offre un varco «Si tu [...] lis, cette chambre paraitra aussi vaste que le ciel, aussi odorante qu'un verger. L'univers est une chambre de prison, c'est le livre qui en détient la clé» (pp. 168-169). Il potere salvifico della letteratura anticipa la vera libertà che la protagonista potrà gustare ancora una volta.

2 Agli eventi relativi al momento presente e alle sue disavventure, Zoubida intervalla i ricordi del passato: l'incontro con il suo interlocutore, Alfred; la relazione sincera tra quest'ultimo e il padre; l'inizio delle vicissitudini della donna; la sua amicizia con Salma; la sua attività lavorativa all'università che la metterà in contatto con l'uomo che le cambierà per sempre il destino. Oltre a questo, la ricerca della verità che riguarda la storia familiare del padre: il mutismo del genitore, il silenzio della madre che cerca di tenere la figlia lontano da quel passato misterioso non impediscono all'ostinazione di Zoubida di scoprire il segreto che li obbliga a vivere da proscritti.

3 Una vicenda drammatica che svela il clima storico dell'Algeria degli anni Ottanta, un contesto che lo scrittore conosce bene perché proprio in quel periodo vi lavorava in qualità di docente. Si tratta di un paese in cui gli estremismi islamici si insinuano a livello sociale in una realtà in tensione tra un passato tradizionalista e un futuro reso incerto dal processo di trasformazione che sta interessando la società dopo i lunghi anni di guerra che hanno portato all'indipendenza. Una discesa agli inferi che lascia uno spiraglio finale e permette all'eroina di trovare una relativa pace grazie a un incontro fortunato che le cambierà la vita quando tutto sembrava perduto. Nessuna traccia di amarezza nelle sue parole, nessuna accusa a coloro che le hanno imposto tormenti e guai. Zoubida è una ribelle che si muove in un contesto spazio-temporale al tempo stesso fluido, sospeso e ben definito, realistico.

4 Bled merita di essere letto per quella speranza che lo scrittore è capace di instillare in tutti coloro che affrontano la vita con coraggio e determinazione, anche quando tutto sembra perduto. 